\title{
Twenty-five-year outcomes after multiple internal thoracic artery bypass
}

\author{
Cyrus J. Parsa, MD, ${ }^{\mathrm{a}}$ Linda K. Shaw, MS, ${ }^{\mathrm{b}}$ J. Scott Rankin, MD, ${ }^{\mathrm{c}}$ Mani A. Daneshmand, MD, ${ }^{\mathrm{a}}$ \\ Jeffrey G. Gaca, MD, ${ }^{a}$ Carmelo A. Milano, MD, ${ }^{a}$ Donald D. Glower, MD, ${ }^{a}$ and Peter K. Smith, MD $^{\mathrm{a}}$
}

\begin{abstract}
Objective: Coronary artery bypass grafting with multiple internal thoracic artery grafts is currently controversial. This study assessed single institutional outcomes with multiple internal thoracic artery grafting for guidance with future clinical decisions.
\end{abstract}

\begin{abstract}
Methods: In 19,482 patients undergoing multivessel coronary artery bypass grafting (1984-2009), baseline characteristics were recorded in a prospective databank, and follow-up was obtained by questionnaires, phone contact, or National Death Index. Outcomes examined were subsequent myocardial infarction, percutaneous coronary intervention, reoperative coronary artery bypass grafting, all-cause death, and a composite of the 4 . Three groups were defined: (1) no internal thoracic artery graft (1874/19,482 or 9\%); (2) single internal thoracic artery grafts and adjunctive venous conduits (single internal thoracic artery; $16,881 / 19,482$ or $87 \%$ ); and (3) multiple internal thoracic artery grafts (728/19,482 or 4\%). Multivariable Cox modeling adjusted for differences in baseline characteristics, and comparisons were performed using area under the curve analysis.
\end{abstract}

Results: Differences in baseline characteristics for the no internal thoracic artery graft, single internal thoracic artery, and multiple internal thoracic artery groups were as follows: median age 66, 64, and 59 years, respectively; congestive heart failure $22 \%, 18 \%$, and $13 \%$, respectively; ejection fraction $0.50,0.52$, and 0.51 , respectively; reoperation $10 \%, 3 \%$, and $7 \%$, respectively; diabetes $27 \%, 30 \%$, and $15 \%$, respectively; and female gender $33 \%, 28 \%$, and $20 \%$, respectively. No differences existed in the median number of diseased vessels $(3,3$, and 3 , respectively) or number of grafts per patient (3,3, and 3, respectively). Composite outcome improved with increasing internal thoracic artery grafts, whether assessing unadjusted or risk-adjusted data. Compared with no internal thoracic artery graft, the adjusted hazard ratio was 0.79 (confidence interval, 0.74-0.83) for single internal thoracic artery grafting and 0.70 (confidence interval, 0.62-0.80) for multiple internal thoracic artery grafting (both $P<.001$ ), reducing risk by $21 \%$ and $30 \%$, respectively.

Conclusions: This study confirms improved patient outcomes with multiple internal thoracic artery grafting, achieving half again as much benefit as single internal thoracic artery grafting alone. The data suggest that increasing application of multiple internal thoracic artery grafting should be encouraged to mitigate the inherent risks and costs of long-term cardiac events. (J Thorac Cardiovasc Surg 2013;145:970-5)

From multiple analyses, it is clear that saphenous veins used for coronary artery bypass grafting $(\mathrm{CABG})$ have limited life $\operatorname{span}^{1}$ and that internal thoracic artery (ITA) conduits improve graft patency and clinical results. ${ }^{2-8}$ Although a right ITA to left anterior descending (LAD) coronary bypass was among the first coronary revascularizations performed and reported in $1967,,^{9}$ the subject remained

From the Duke University Medical Center, ${ }^{\mathrm{a}}$ Durham, NC; Duke Clinical Research Institute, ${ }^{\mathrm{b}}$ Durham, NC; and Centennial Medical Center, ${ }^{\mathrm{c}}$ Vanderbilt University, Nashville, Tenn.

A grant from the National Heart, Lung, and Blood Institute and CTS Network supported the research of Dr Parsa.

Disclosures: Authors have nothing to disclose with regard to commercial support.

Read at the 92nd Annual Meeting of The American Association for Thoracic Surgery, San Francisco, California, April 28-May 2, 2012.

Received for publication April 30, 2012; revisions received Oct 9, 2012; accepted for publication Nov 6, 2012; available ahead of print Feb 11, 2013.

Address for reprints: Cyrus J. Parsa, MD, Division of Thoracic and Cardiovascular Surgery, Harbin Clinic, Rome, GA 30165 (E-mail: cyrus.parsa@ harbinclinic.com). $0022-5223 / \$ 36.00$

Copyright (c) 2013 by The American Association for Thoracic Surgery

http://dx.doi.org/10.1016/j.jtcvs.2012.11.093 controversial until 1986 when Loop and associates ${ }^{8}$ published significant clinical benefits over venous conduits at 10 -year follow-up. Numerous studies also have documented benefits of multiple ITA (MITA) grafts over single ITA (SITA) conduits with adjunctive veins, including reduction in death rates and late cardiac events. ${ }^{2-7}$

Despite this information, MITA grafts recently were used in only $12 \%$ of CABG cases in Europe ${ }^{10}$ and $4 \%$ of CABG cases in the United States. ${ }^{11}$ Even in the SYNTAX trial, MITA grafting was performed in only $26 \%$ of patients. ${ }^{12}$ Perhaps with all of the available positive data, surgeons should focus on expanding MITA graft procedures. To better illuminate this issue, a single institutional experience with MITA grafting was examined using a validated database with rigorous follow-up to the ultra long-term. The goal was to obtain guidance with future clinical decisions.

\section{MATERIALS AND METHODS}

Over the 25-year period between 1984 and 2009, 19,482 isolated CABG procedures were performed for multivessel coronary artery disease at Duke 

Abbreviations and Acronyms
$\mathrm{CABG}=$ coronary artery bypass grafting
ITA = internal thoracic artery
$\mathrm{LAD}=$ left anterior descending
MACE $=$ major adverse cardiac events
MI $=$ myocardial infarction
MITA $=$ multiple internal thoracic artery
NITA $=$ no internal thoracic artery
PCI = percutaneous coronary intervention
$\mathrm{RCA}=$ right coronary artery
SITA $=$ single internal thoracic artery

University Medical Center. All relevant baseline and operative characteristics were recorded prospectively, ${ }^{5}$ and analysis was performed by the independent statisticians at the Duke Cardiovascular Databank. By using mailed questionnaires, phone contact, or National Death Index data, 4 outcome variables were monitored continuously by the Duke Outcome Group: nonfatal myocardial infarction (MI), subsequent percutaneous coronary intervention (PCI), redo CABG, and all-cause death. Institutional review board approval was obtained before beginning the analysis, and informed consent was waived. Three clinical cohorts were defined according to grafting strategy: (1) saphenous vein grafts only (no ITA [NITA] $\mathrm{n}=1074$; $9 \%$ ), (2) SITA and adjunctive vein grafts (SITA $\mathrm{n}=16,881 ; 87 \%$ ), and (3) MITA grafts (MITA $n=728 ; 4 \%$ ). In the analysis, patients with MITA grafts were defined only by the number of distal ITA anastomoses. Unlike earlier studies that described MITA as ITA grafts to 2 coronary systems, the data set in the last decade was changed to a Society of Thoracic Surgeons 2.61 format, and specific distal anastomoses were not available. Free ITAs comprised less than $5 \%$ of arterial grafts ${ }^{2}$ and therefore were not differentiated. Likewise, radial artery grafts were performed in only $256 \mathrm{pa}-$ tients in the whole series and were included with the saphenous vein grafts.

In the analysis, the primary end point was a composite major adverse cardiac events (MACE) outcome of all 4 variables (all-cause death, MI, PCI, and redo $\mathrm{CABG}$ ). Baseline characteristics assessed in the multivariable model were year of surgery, age, gender, race, history of PCI, prior CABG, history of CHF, New York Heart Association class, presence of diabetes, left ventricular ejection fraction, presence of left main disease, number of diseased vessels, presence and grade of mitral insufficiency, history of tobacco use, hypertension, peripheral vascular disease, cerebrovascular disease, history of MI, number of grafts created, and presence of renal failure.

Unadjusted cumulative incidence data for each of the 3 groups (NITA, SITA, and MITA) were calculated for each outcome variable: nonfatal MI, subsequent PCI, redo CABG, and all-cause death. Cumulative event rates were calculated using the Kaplan-Meier method as a function of time after the index surgery. Cox proportional hazards modeling was used to adjust for differences in patient baseline characteristics between groups. Cumulative incidence curves for the 4 outcome variables again were generated after Cox model adjustment. Event-free survival curves (freedom from composite MACE outcome) were examined without and with risk adjustment by the Cox model. Comparisons between groups in the adjusted setting were performed using area under the curve analysis of composite outcome.

\section{RESULTS}

Baseline characteristics of the 3 populations were different, with the NITA group being older with more significant preoperative comorbidities and MITA exhibiting less serious risk profiles (Table 1). Differences in baseline characteristics in the NITA, SITA, MITA groups were as follows: median age 66,64 , and 59 years, respectively; congestive heart failure $22 \%, 18 \%$, and $13 \%$, respectively; ejection fraction $0.50,0.52$, and 0.51 , respectively; reoperation $10 \%, 3 \%$, and $7 \%$, respectively; diabetes $27 \%, 30 \%$, and $15 \%$, respectively; and female gender $33 \%, 28 \%$, and $20 \%$, respectively. No statistical differences existed in the median number of diseased vessels $(3,3$, and 3, respectively) or number of grafts required per patient $(3,3$, and 3 , respectively).

Unadjusted cumulative event analyses suggested that addition of more ITA conduits was associated with progressively fewer late complications (Figure 1). However, after risk adjustment of the raw cumulative event data, differences between groups narrowed as the worse baseline risk profiles of the NITA group were taken into account. However, even in the risk-adjusted analysis, adding more ITA grafts progressively reduced MACE complications over the 25-year study period (Figure 2). The exception was adjusted mortality, which was similar between SITA and MITA groups. However, this level of mortality was achieved in the SITA group at the cost of more reinterventions (Table 2).

Likewise, unadjusted freedom from MACE composite outcome improved as more ITAs were used (Figure 3). After statistical adjustment, the differences narrowed, but a statistically and clinically significant benefit persisted for using more ITA grafts. Compared with NITA, the hazard ratio was 0.79 (confidence interval, 0.74-0.83) for SITA, and it was 0.70 (confidence interval, 0.62-0.80) for MITA (both $P<.001$ ) (Table 2). Over the 25 years of follow-up, average area under the curve improvement in adjusted composite outcome was $21 \%$ for SITA versus NITA and $30 \%$ for MITA versus NITA.

\section{DISCUSSION}

The present analysis adds to the many studies showing improved long-term results with MITA grafting. ${ }^{13-17}$ However, it is interesting to simultaneously assess NITA procedures, so that both SITA and MITA can be placed numerically into therapeutic context. Over 25 years of follow-up, SITA grafting reduced the composite event rate by $21 \%$, and the addition of another ITA graft (MITA) reduced events by half again as much. The precise documentation of nonfatal complications is an important feature of this study and further illuminates the therapeutic landscape of ITA grafting. It is now fairly certain that general patient outcomes are improved by MITA grafting, but this study showed a new twist. In the age of aggressive interventional cardiology, adjusted SITA mortality differed minimally from MITA, but this result was achieved at a cost of more nonfatal events and interventions. This finding is different from previous time frames and may demonstrate how practice outcomes are changing over time. Other factors also may have been operative (see "Study Limitations"), 
TABLE 1. Baseline characteristics

\begin{tabular}{|c|c|c|c|c|}
\hline Variable & NITA & SITA & MITA & $\begin{array}{c}P \\
\text { value }\end{array}$ \\
\hline No. $(19,482)$ & $1874(9.6 \%)$ & $16,881(86.6 \%)$ & $728(3.7 \%)$ & - \\
\hline Median age (y) & 66 & 64 & 59 & $<.001$ \\
\hline Gender female & $33.3 \%$ & $28.5 \%$ & $19.8 \%$ & $<.001$ \\
\hline $\mathrm{CHF}$ & $21.7 \%$ & $17.6 \%$ & $12.6 \%$ & $<.001$ \\
\hline Reoperation & $10.5 \%$ & $3.0 \%$ & $6.9 \%$ & $<.001$ \\
\hline Prior PCI & $18.6 \%$ & $13.8 \%$ & $11.3 \%$ & $<.001$ \\
\hline Diabetes & $27.3 \%$ & $29.9 \%$ & $14.7 \%$ & $<.001$ \\
\hline Hypertension & $61.5 \%$ & $63.5 \%$ & $42.9 \%$ & $<.001$ \\
\hline $\begin{array}{l}\text { Cerebrovascular } \\
\text { disease }\end{array}$ & $14.1 \%$ & $11.0 \%$ & $4.5 \%$ & $<.001$ \\
\hline $\begin{array}{l}\text { Peripheral vascular } \\
\text { disease }\end{array}$ & $17.7 \%$ & $14.6 \%$ & $10.9 \%$ & $<.001$ \\
\hline COPD & $9.6 \%$ & $8.2 \%$ & $3.9 \%$ & $<.001$ \\
\hline Median LVEF & 0.50 & 0.52 & 0.51 & $<.001$ \\
\hline Renal failure & $2.4 \%$ & $2.4 \%$ & $1.0 \%$ & .04 \\
\hline 3-vessel disease & $69 \%$ & $78 \%$ & $81 \%$ & .31 \\
\hline LM disease & $26.2 \%$ & $26.0 \%$ & $23.5 \%$ & .31 \\
\hline Median no. of grafts & 3 & 3 & 3 & NS \\
\hline
\end{tabular}

including the fact that all survival curves eventually come back together, and ultra long-term follow-up can be associated with decreasing survival differences.
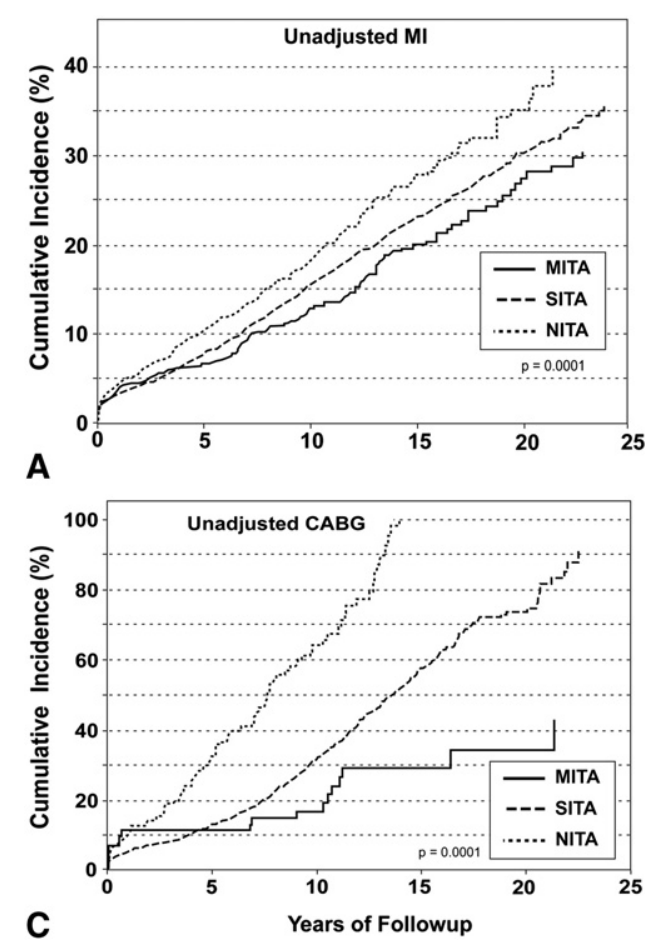

So why has MITA grafting not been embraced by American surgeons in the face of such compelling data? Even in our center, the rate of MITA grafting was only $4 \%$, similar to current national rates in the Society of Thoracic Surgeons Database. ${ }^{11}$ Certainly, MITA procedures require more operative time and are more tedious. ${ }^{2,4,5}$ Special technical facility and experience also may be necessary, compared with routine vein grafts. It can be reasoned that tolerance of these minor technical inconveniences may be worth achieving better outcomes for the patients. The general morbidity of MITA grafting may be increased slightly, especially regarding sternal discomfort and perioperative blood requirement. Sternal wound healing and infection have been reported to be problems with MITA grafting, especially in diabetic persons. ${ }^{18}$ However, many authors have minimized sternal complications by approaches such as strict infection control, skeletonized ITA harvesting, and use of topical antibiotic irrigation to minimize sternal infection. ${ }^{19-21}$ Thus, it is now clear that routine MITA grafting is safe, even in diabetic patients, and one might suggest that no excuse exists for the low national MITA rates in the United States.

It has been shown that MITA grafting techniques can be used in excess of $75 \%$ of patients with multivessel disease, and that the relative benefits are just as great in diabetic patients and the elderly. ${ }^{5}$ So, it is reasonable to assume that cardiac surgeons should seriously consider increasing
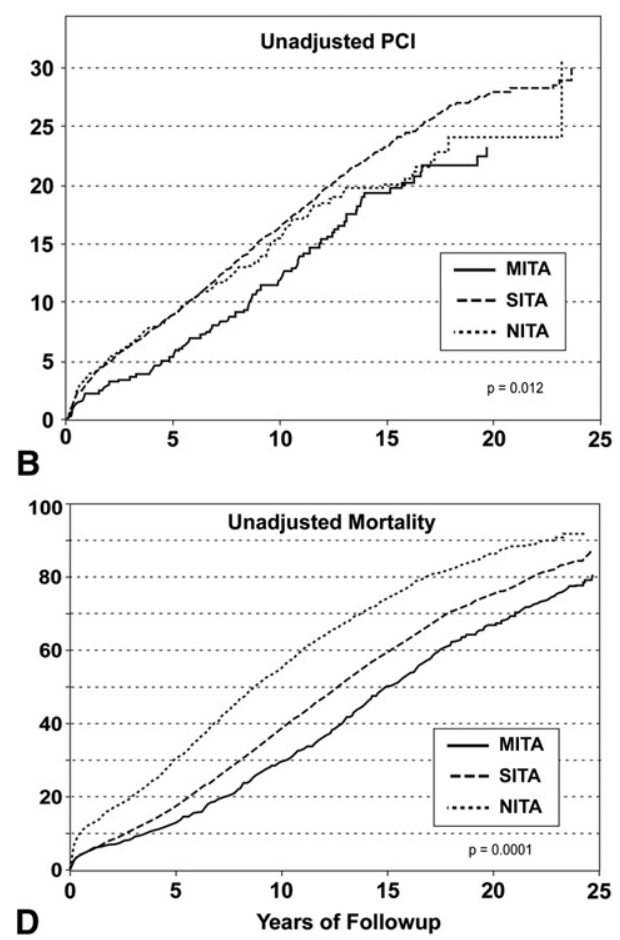

FIGURE 1. Unadjusted cumulative incidence data: nonfatal MI (A), PCI (B), redo CABG (C), and all-cause mortality (D). Number of patients at risk is shown in Figure 3. MI, Myocardial infarction; PCI, percutaneous coronary intervention; MITA, multiple internal thoracic artery; SITA, single internal thoracic artery; NITA, no internal thoracic artery; $C A B G$, coronary artery bypass grafting. 


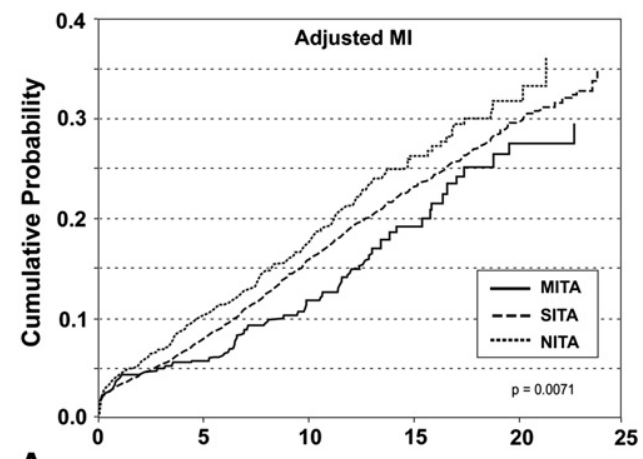

A
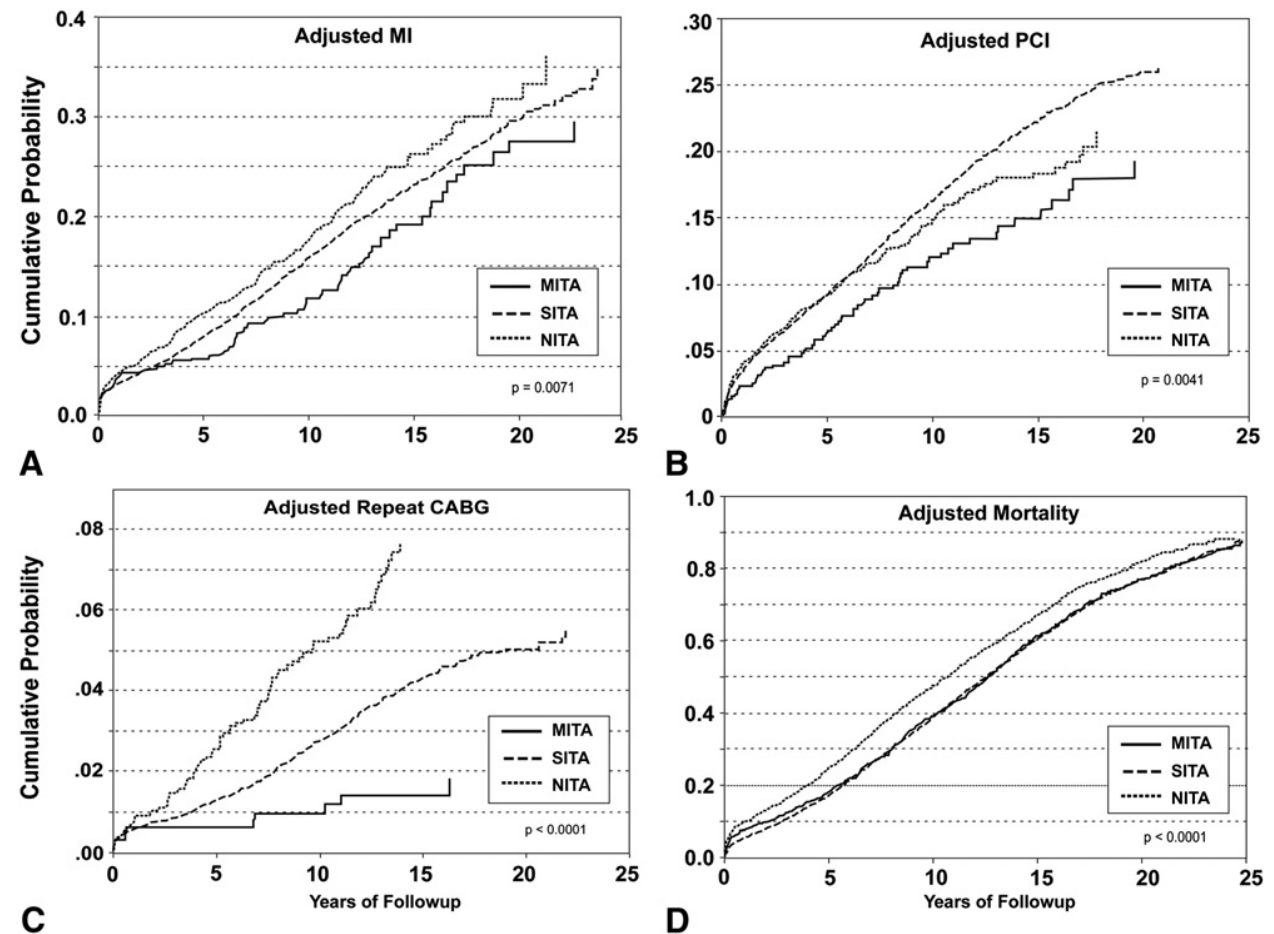

FIGURE 2. Risk-adjusted cumulative incidence data: nonfatal MI (A), PCI (B), redo CABG (C), and all-cause mortality (D). Number of patients at risk is shown in Figure 3. MI, Myocardial infarction; PCI, percutaneous coronary intervention; MITA, multiple internal thoracic artery; SITA, single internal thoracic artery; NITA, no internal thoracic artery; $C A B G$, coronary artery bypass grafting.

MITA use, to the benefit of the population with coronary disease. In fact, if surgical therapy is to maintain relevance in the age of improving interventional cardiologic techniques, surgeons need to optimize outcomes in whatever way possible, and more MITA grafting is one logical candidate. As 3-year SYNTAX results have begun to show an outcome advantage of CABG over PCI for patients with a high SYNTAX score (a benefit driven by lower reintervention rates), it must be acknowledged that $26 \%$ of patients in that study underwent MITA grafting. ${ }^{12}$ Replicating SYNTAX results in the "real world" may warrant increased attention to augmenting MITA use in the general population undergoing $\mathrm{CABG}$.

TABLE 2. Adjusted hazard ratios

\begin{tabular}{|c|c|c|c|c|}
\hline \multirow[b]{2}{*}{$\begin{array}{c}\text { End } \\
\text { point }\end{array}$} & \multicolumn{4}{|c|}{ HR (CI) } \\
\hline & SITA vs NITA & MITA vs NITA & MITA vs SITA & $\begin{array}{c}P \\
\text { value } \\
(2 d f) \\
\end{array}$ \\
\hline Death & $0.77(0.72-0.82)$ & $0.73(0.63-0.84)$ & $0.95(0.83-1.08)$ & $<.0001$ \\
\hline CABG & $0.57(0.45-0.73)$ & $0.21(0.10-0.42)$ & $0.36(0.19-0.71)$ & $<.0001$ \\
\hline PCI & $1.12(0.97-1.29)$ & $0.77(0.58-1.01)$ & $0.68(0.53-0.88)$ & .0041 \\
\hline MI & $0.85(0.75-0.96)$ & $0.69(0.53-0.90)$ & $0.81(0.64-1.03)$ & .0071 \\
\hline MACE & $0.79(0.74-0.83)$ & $0.70(0.62-0.80)$ & $0.89(0.80-1.00)$ & $<.0001$ \\
\hline
\end{tabular}

Numerous studies also support the use of more radial artery grafts. With the use of careful harvesting and preparation techniques, as well as routine calcium channel blockade and fresh heparinized blood distension, the Brompton Hospital study ${ }^{22}$ showed excellent results with radial artery grafting, achieving 5-year patency rates in excess of $95 \%$, and approaching those of ITA grafts. Numerous reports of radial artery grafting also have shown better clinical outcomes. ${ }^{23-25}$ Many centers now have undertaken programs of "all-arterial" coronary bypass, and with 2 ITA grafts and 2 radial arteries, most patients with multivessel disease can undergo all-arterial bypass. It should be emphasized that MITA grafting should be the central feature of such an approach.

Although left ITA grafts to the LAD or circumflex coronary arteries have approximately $100 \%$ patency, results with the right ITA graft often have been suboptimal. Right ITA grafts to the circumflex coronary artery through the transverse sinus can exhibit kinking, ${ }^{2}$ although methods such as retro-caval placement have shown promise. Right ITA grafts to the distal right coronary artery (RCA) can get stretched over the right atrium, and right ITA to distal RCA bypass frequently is not feasible because of length limitations. With experience, these problems can be overcome and MITA grafting facilitated by several techniques. Skeletonized harvesting or pedicle "slits" can increase ITA length, and a "pulley stitch" can decrease the distance 

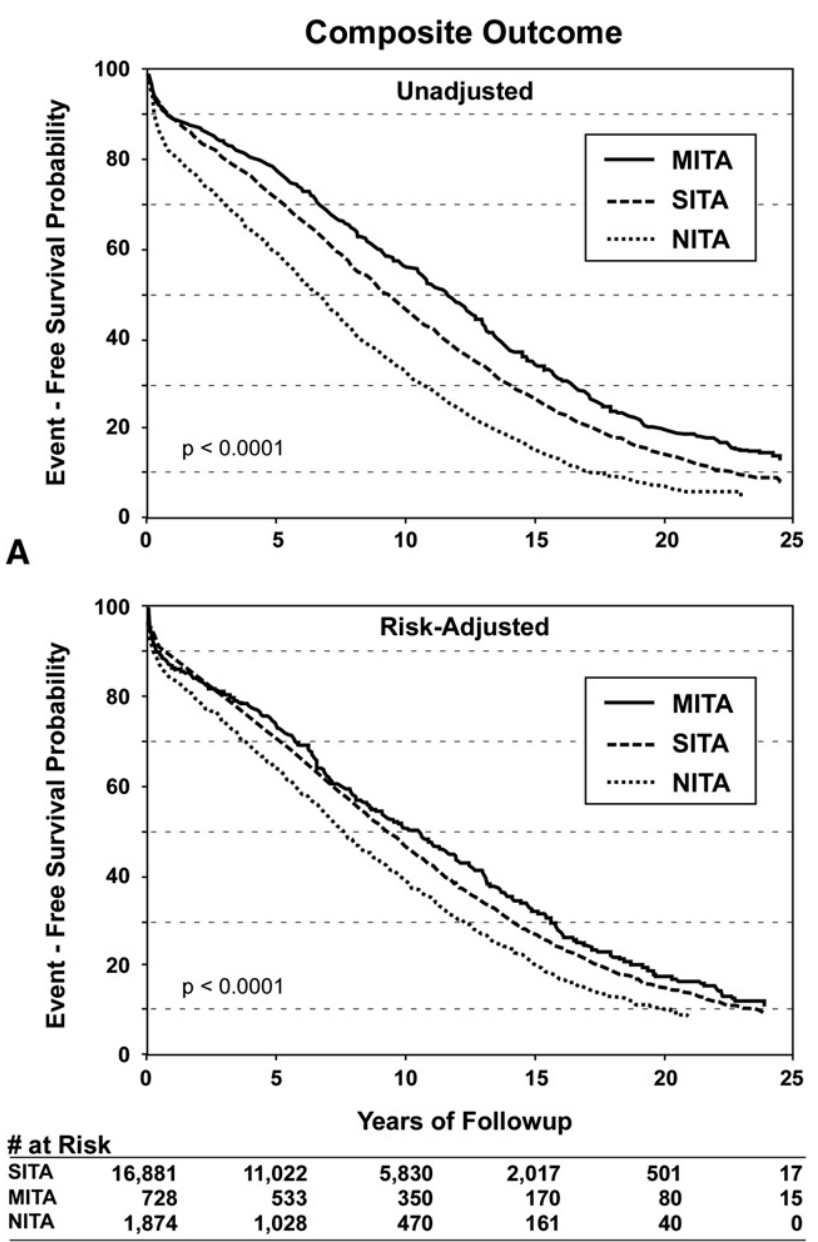

B

FIGURE 3. Event-free survival probability for composite outcome: unadjusted (A) and risk-adjusted (B) data. MITA, Multiple internal thoracic artery; SITA, single internal thoracic artery; NITA, no internal thoracic artery.

to the distal RCA, allowing more distal anastomoses without tension. ${ }^{5}$ Most important, use of the right ITA to graft the LAD across the midline achieves an approximate $100 \%$ patency for the right ITA graft and has been the dominant LAD grafting technique in several series (two thirds of MITA cases in our series ${ }^{2,5}$ ). Covering the conduit with the thymic fat pad at the end of the procedure prevents subsequent injury during reentry (although only $4 \%-5 \%$ required reoperation at 20 years). Free ITA grafts also improve use with difficult anatomy, and again, free grafts have excellent patencies. So as long as the 2 largest coronary systems are grafted with ITAs, the exact combination is not critical, but it is important to use highpatency configurations. ${ }^{26}$ When radial arteries are added for additional grafts (together with frequent use of sequential arterial grafts as an "all-arterial" configuration), late complications of saphenous vein closures can be markedly reduced. $^{27}$

\section{Study Limitations}

The present study is limited by observational design. Undefined confounding variables or treatment selection biases are always possible. The lack of definition of distal vessel anastomoses in the past decade also could have been problematic. We have previously shown that MITA grafts are most effective prognostically if placed to 2 different coronary systems. Sequential MITA grafts to the same coronary system influence outcome more like single ITA bypass, and including sequential grafts with the MITA group in this analysis could have weakened observed MITA benefits. Thus, the effects of MITA grafting on both event rates and mortality differences could have been underestimated in this study. Moreover, all 3 groups had different baseline characteristics, and inadequacies in risk adjustment could have existed. Coronary risk factor analysis and follow-up techniques in the Duke Databank are now mature, but follow-up can be difficult. However, the techniques used by the independent Duke Followup Group are state of the art, and all-important coronary variables are defined precisely in the Databank. In fact, Duke observational results have almost exactly mirrored most randomized trials, ${ }^{28}$ adding credence to the current data. At present, randomized MITA comparisons are being generated ${ }^{29}$ and should further improve our understanding. However, longer-term data spanning greater than 2 decades, as presented in this article, are useful in providing guidance for current clinical management.

\section{CONCLUSIONS}

This study and other recent literature suggest that increasing application of MITA grafting should be encouraged to mitigate the inherent risks and costs of long-term cardiac events after CABG. In coming years, MITA and all-arterial coronary bypass could play an increasingly important role in the treatment of coronary artery disease.

\section{References}

1. Alexander JH, Hafley G, Harrington RA, et al. Efficacy and safety of edifoligide, an E2F transcription factor decoy, for prevention of vein graft failure following coronary artery bypass graft surgery: PREVENT IV: a randomized controlled trial. JAMA. 2005;294:2446-54.

2. Rankin JS, Newman GE, Bashore TM, et al. Clinical and angiographic assessment of complex mammary artery bypass grafting. J Thorac Cardiovasc Surg. 1986;92:832-46.

3. Lytle BW, Blackstone EH, Loop FD, et al. Two internal thoracic artery grafts are better than one. J Thorac Cardiovasc Surg. 1999;117:855-72.

4. Burfeind WR, Glower DD, Wechsler AW, et al. Single versus multiple internal mammary artery grafting for coronary artery bypass: 15-year follow-up of a clinical practice trial. Circulation. 2004;110(Suppl II):II27-35.

5. Rankin JS, Tuttle RH, Wechsler AS, et al. Techniques and benefits of multiple internal mammary artery bypass at 20-years of followup. Ann Thorac Surg. 2007;83:1549-55.

6. Lytle BW, Cosgrove DM, Saltus GL, et al. Multivessel coronary revascularization without saphenous vein: long-term results of bilateral internal mammary artery grafting. Ann Thorac Surg. 1983;36:540-51.

7. Lytle BW, Blackstone EH, Sabik JF, et al. The effect of bilateral internal thoracic artery grafting on survival during 20 postoperative years. Ann Thorac Surg. 2004; 78:2005-12. 
8. Loop FD, Lytle BW, Cosgrove DM, et al. Influence of the internal mammary artery graft on 10-year survival and other cardiac events. N Engl J Med. 1986;314:1-9.

9. Kolessov VI. Mammary artery-coronary artery anastomosis as method of treatment for angina pectoris. J Thorac Cardiovasc Surg. 1967;54:535-44.

10. Kappetein AP, Dawkins KD, Mohr FW, et al. Current percutaneous coronary intervention and coronary artery bypass grafting practices for three-vessel and left main coronary artery disease. Insights from the SYNTAX run-in phase. Eur J Cardiothorac Surg. 2006;29:486-91.

11. ElBardissi AW, Aranki SF, Sheng S, et al. Trends in isolated coronary artery bypass grafting: An analysis of the STS adult cardiac surgery database. J Thorac Cardiovasc Surg. 2012;143:273-81.

12. Serruys PW, Morice M-C, Kappetein AP, et al. for the SYNTAX Investigators. Percutaneous coronary intervention versus coronary-artery bypass grafting for severe coronary artery disease. N Engl J Med. 2009;360:961-72.

13. Berreklouw E, Rademakers PPC, Koster JM, et al. Better ischemic event-free survival after two internal thoracic artery grafts: 13 years of follow-up. Ann Thorac Surg. 2001;72:1535-41.

14. Endo M, Nishida H, Tomizawa Y, et al. Benefit of bilateral over single internal mammary artery grafts for multiple coronary artery bypass grafting. Circulation. 2001;104:2164-70.

15. Tavilla G, Kappetein AP, Braun J, et al. Long-term follow-up of coronary artery bypass grafting in three-vessel disease using exclusively pedicled bilateral internal thoracic and right gastroepiploic arteries. Ann Thorac Surg. 2004;77:794-9.

16. Calafiore AM, Di Giammarco G, Teodori G, et al. Late results of first myocardial revascularization in multiple vessel disease: single versus bilateral internal mammary artery with or without saphenous veins. Eur J Cardiothorac Surg. 2004;26:542-8.

17. Guru V, Fremes SE, Tu JV. How many arterial grafts are enough? A population based study of mid-term outcomes. J Thorac Cardiovasc Surg. 2006;131:1021-8.

18. Savage EB, Grab JD, O'Brien SM, et al. Use of both internal thoracic arteries in diabetic patients increases deep sternal wound infection. Ann Thorac Surg. 2007; 83:1002-6.
19. Graf K, Sohr D, Haverich A, et al. Decrease of deep sternal surgical site infection rates after cardiac surgery by a comprehensive infection control program. Interact Cardiovasc Thorac Surg. 2009;9:282-6.

20. De Paulis R, de Notaris S, Scaffa R, et al. The effect of bilateral internal thoracic artery harvesting on superficial and deep sternal infection: the role of skeletonization. J Thorac Cardiovasc Surg. 2005;129:536-43.

21. Vander Salm TJ, Okike ON, Pasque MK, et al. Reduction of sternal infection by application of topical vancomycin. J Thorac Cardiovasc Surg. 1989;98:618-22.

22. Collins P, Webb CM, Chong CF, et al. Radial artery versus saphenous-vein patency randomized trial: five-year angiographic follow-up. Circulation. 2008; 117:2859-64.

23. Tranbaugh RF, Dimitrova KR, Friedmann P, et al. Radial artery conduits improve long-term survival after coronary artery bypass grafting. Ann Thorac Surg. 2010; 90:1165-72

24. Schwann TA, Zacharias A, Riordan CJ, et al. Sequential radial artery grafts for multivessel coronary artery bypass graft surgery: 10-year survival and angiography results. Ann Thorac Surg. 2009;88:31-9.

25. Jung S-H, Song H, Choo SJ, et al. Comparison of radial artery patency according to proximal anastomosis site: direct aorta to radial artery anastomosis is superior to radial artery composite grafting. J Thorac Cardiovasc Surg. 2009;138:76-83.

26. Parsa CJ, Daneshmand MA, Gaca JG, Rankin JS. Arterial bypass grafting of the coronary circulation. HSR Proc Intensive Care Cardiovasc Anesth. 2011:3:237-4

27. Locker C, Schaff HV, Dearani JA, et al. Multiple arterial grafts improve late survival of patients undergoing coronary artery bypass graft surgery: analysis of 8622 patients with multivessel disease. Circulation. 2012;126:1023-30.

28. Velazquez EJ, Lee KL, Deja MA, et al. Coronary-artery bypass surgery in patients with left ventricular dysfunction. N Engl J Med. 2011;364:1607-16.

29. Taggart DP, Altman DG, Gray AM, et al. Randomized trial to compare bilatera vs. single internal mammary coronary artery bypass grafting: 1-year results of the Arterial Revascularisation Trial (ART). Eur Heart J. 2010;31:2470-81. 